\title{
Managing Common Comorbidities in Heart Failure
}

\author{
Dr. Phyllis Sin, Dr. Rohan Sanjanwala, Dr. Shelley Zieroth
}

\begin{abstract}
About the Authors
Phyllis Sin and Shelley Zieroth are with the University of Manitoba, Winnipeg, Manitoba

Rohan Sanjanwala and Shelley Zieroth are with the WRHA Cardiac Sciences Program, Winnipeg, Manitoba

Corresponding Author: szieroth@sbgh.mb.ca

Submitted: January 29, 2020. Accepted: February 5. Published: April 8, 2020. DOI: 10.22374/cjgim.v15iSP1.422.
\end{abstract}

\begin{abstract}
Heart failure increases in prevalence with age and is usually associated with various cardiac and non-cardiac comorbidities. For common coexisting conditions such as renal dysfunction, anemia, and type 2 diabetes mellitus, important pathophysiologic links have been implicated between cardiac dysfunction and the underlying condition. Indeed, the number and severity of comorbidities in the setting of heart failure is an important driver of prognosis. By targeting the management of coexisting diseases, it may be possible to improve functional capacity, quality of life and perhaps even overall mortality in heart failure patients. Recent clinical trial data has provided insights into cardio-renal interactions in acute heart failure, the impact of iron replacement therapy in iron-deficient heart failure patients, and the role of pharmacologic therapies to prevent heart failure-related events in high-risk patients with type 2 diabetes.
\end{abstract}

\section{Resume}

La prévalence de l'insuffisance cardiaque augmente avec l'âge et est généralement associée à diverses comorbidités cardiaques et non cardiaques. Pour les affections coexistantes courantes telles que le dysfonctionnement rénal, l’anémie et le diabète sucré de type 2, des liens physiopathologiques importants ont été mis en évidence entre le dysfonctionnement cardiaque et l'affection sous-jacente. En effet, le nombre et la gravité des comorbidités dans le contexte de l'insuffisance cardiaque est un facteur important de pronostic. En ciblant la gestion des maladies coexistantes, il peut être possible d'améliorer la capacité fonctionnelle, la qualité de vie et peutêtre même la mortalité globale chez les patients souffrant d'insuffisance cardiaque. Les données d'essais cliniques récents ont permis de mieux comprendre les interactions cardio-rénales en cas d'insuffisance cardiaque aiguë, l'impact de la thérapie de remplacement du fer chez les patients souffrant d'insuffisance cardiaque ferreuse et le rôle des traitements pharmacologiques pour prévenir les événements liés à l'insuffisance cardiaque chez les patients à haut risque atteints de diabète de type 2 .

Heart failure (HF) is a chronic disease that is associated with significant morbidity and mortality. There are currently 600,000 Canadians living with HF, and these numbers are expected to rise as the population ages. HF hospitalizations have increased annually across Canada, with 60,000 reported in 2013-2014 according to the Canadian Institute for Health Information data, with a $13 \%$ relative increase over the past 6 years. It is estimated that HF results in direct costs of more than $\$ 2.8$ billion per year in Canada. ${ }^{1}$ Typically, HF patients with multiple comorbidities are older with more advanced HF, higher NYHA class and increased prevalence of cardiac complications such as coronary artery disease and atrial fibrillation. However, non-cardiac comorbid conditions are independently associated with a higher risk of mortality and HF hospitalization. ${ }^{2}$

A higher burden of comorbidities in patients with HF is associated with repeated hospitalization and poor outcomes. ${ }^{3}$ 
It is estimated that male and female patients with HF have a mean (standard deviation) of 2.62(1.55) and 2.8(1.61) comorbidities, respectively. ${ }^{4}$ In a systemic review that included over 60,000 HF patients, four studies observed an increased mortality risk (relative risk $[R R]=1.21 ; 95 \%$ confidence interval $[\mathrm{CI}]$ : 1.13-1.29) per point increase in Charlson Comorbidity Index (CCI) score, a recognized measure that integrates the prognostic impact of 22 comorbid conditions. ${ }^{3}$ Increased mortality was seen with greater numbers of comorbid conditions and a higher CCI score. ${ }^{3}$ Furthermore, the European HF Pilot Survey reported that most HF patients (74\%) had at least one comorbidity; the most prevalent being chronic kidney disease (CKD) (41\%) followed by anemia (29\%), and diabetes (29\%). There are also data to suggest patients with comorbidities are less likely to receive evidencebased, guideline-directed medical therapy (GDMT) given their frequent exclusion from clinical trials. ${ }^{3,5}$ For example, in the landmark Effects of Enalapril on Mortality in Severe Congestive HF (CONSENSUS) trial, patients with a serum creatinine $>300$ $\mu \mathrm{mol} / \mathrm{L}$ were excluded. ${ }^{6}$ This remains true in more recent HF studies including the Prospective Comparison of ARNi with ACEi to Determine Impact on Global Mortality and Morbidity in Heart Failure trial (PARADIGM-HF), the Efficacy and Safety of LCZ696 Compared to Valsartan, on Morbidity and Mortality in Heart Failure Patients With Preserved Ejection Fraction trial (PARAGON-HF) and the Study to Evaluate the Effect of Dapagliflozin on the Incidence of Worsening Heart Failure or Cardiovascular Death in Patients With Chronic Heart Failure (DAPA-HF) which excluded patients with an estimated glomerular filtration rate $(e G F R)<30 \mathrm{~mL} / \mathrm{min} / 1.73 \mathrm{~m}^{2}{ }^{7-9}$ This review examines non-cardiac comorbidities in HF patients, focusing on the prevalence, management, and prognostic implications.

\section{Renal Dysfunction}

CKD, defined as an eGFR $<60 \mathrm{~mL} / \mathrm{min} / 1.73 \mathrm{~m}^{2}$ (Table 1 ), is associated with both all-cause mortality (hazard ratio [HR] = 1.50, 95\% CI: 1.06-2.11) and hospitalizations in those living with $\mathrm{HF}(\mathrm{HR}=1.59,95 \% \mathrm{CI}: 1.2-2.06){ }^{2}$ The CHARM group looked at both HF with reduced ejection fraction (HFrEF) and HF with preserved ejection fraction (HFpEF) patients with comorbid CKD. In the CHARM-Added, CHARM-Preserved and CHARMAlternative trials, the prevalence of CKD was $33 \%, 35 \%$, and $43 \%$ respectively. ${ }^{10}$ However, in the Acute Decompensated HF National (ADHERE) Registry, a large observational database of patients hospitalized with acute decompensated HF, 59.3\% of men and $67.6 \%$ of women had at least moderate renal dysfunction (eGFR $30-59 \mathrm{~mL} / \mathrm{min} / 1.73 \mathrm{~m}^{2}$ ) at the time of admission. ${ }^{11}$ A meta-analysis of observational studies confirms that HF patients with moderate to severe renal dysfunction have a $>2$-fold increase in mortality risk. ${ }^{12}$ Currently, the Canadian Cardiovascular Society (CCS)
Table 1. National Kidney Foundation Classification of Chronic Renal Dysfunction. $^{46}$

\begin{tabular}{|c|c|}
\hline CKD Stage & eGFR $\left(\mathrm{mL} / \mathrm{min} / 1.73 \mathrm{~m}^{2}\right)$ \\
\hline 1 & $>90$ \\
\hline 2 & $60-89$ \\
\hline 3 & $30-59$ \\
\hline 4 & $15-29$ \\
\hline 5 & $<15$ or on dialysis \\
\hline
\end{tabular}

CKD = chronic kidney disease; eGFR = estimated glomerular filtration rate.

recommends that HFrEF patients with stable, chronic mildto-moderate renal insufficiency should receive GDMT with an angiotensin-converting enzyme inhibitor (ACEi), angiotensin receptor blocker (ARB) or mineralocorticoid receptor antagonist (MRA) for those with an eGFR $>30 \mathrm{ml} . \mathrm{min} / 1.73 \mathrm{~m}^{2}$. Clinicians are advised to expect up to a $30 \%$ rise in serum creatinine from the baseline before it becomes necessary to stop or reduce the dose of the ACEis, ARBs or MRAs. ${ }^{13}$

Diuretic therapy is critical in managing hypervolemia in HF patients. The Diuretic Strategies in Patients with Acute Decompensated HF (DOSE) trial demonstrated no significant difference in patients' global assessment of symptoms or change in renal function when comparing an intravenous bolus loop diuretic strategy with continuous intravenous infusion strategy, or when comparing high vs low dose intravenous loop diuretics among patients with acute decompensated $\mathrm{HF}^{14}$ Furthermore, ultrafiltration is not recommended as first-line management of fluid overload in decompensated HF. The Ultrafiltration Versus Intravenous Diuretics for Patients Hospitalized for Acute Decompensated HF (UNLOAD) trial randomized 200 patients hospitalized for HF with $\geq 2$ signs of hypervolemia to ultrafiltration or intravenous diuretics. Weight loss and net fluid loss at 48 hours were greater in the ultrafiltration group but there was no difference in dyspnea scores. ${ }^{15}$ Based on the results from the Cardiorenal Rescue Study in Acute Decompensated Heart Failure (CARRESS-HF) trial, intravenous diuresis was superior to ultrafiltration for the preservation of renal function and associated with similar weight loss. ${ }^{16} \mathrm{~A}$ higher percentage of patients in the ultrafiltration group had a serious adverse event ( $72 \%$ vs. $57 \%$, $\mathrm{p}=0.03$ ), attributable mainly to higher incidences of kidney failure, bleeding complications, and intravenous catheter-related complications. ${ }^{16}$ These trials were not powered to address major clinical outcomes, and no long-term evaluation of the impact of ultrafiltration on HF or all-cause hospitalizations has been performed. ${ }^{13}$ 
Cardiac and renal dysfunction often occurs in concert with hemodynamic, neurohormonal, vascular, and hematologic consequences. ${ }^{13}$ Cardiorenal syndrome refers to the complex interactions whereby renal dysfunction and HF coexist (Table 2). ${ }^{17}$ Clinical management of cardiorenal syndrome includes diuresis, vasodilator therapy and optimization of GDMT for HFrEF if applicable (Figure 1). ${ }^{13}$ Combination diuretics, where a thiazide diuretic such as hydrochlorothiazide or metolazone is given before loop diuretics, can produce more effective diuresis, can overcome diuretic resistance, and increase fractional sodium excretion. ${ }^{17,18}$ A particular challenge is the absence of any high-quality data for GDMT in chronic cardiorenal syndrome with moderate to severe renal dysfunction, and a multi-specialty team approach should be considered for its management. ${ }^{13}$

\section{Anemia}

Anemia is an established independent predictor of mortality and HF hospitalizations. ${ }^{19}$ Using the World Health Organization definitions of hemoglobin $<13 \mathrm{~g} / \mathrm{L}$ for men and $<12 \mathrm{~g} / \mathrm{L}$ for
Table 2. Acute Dialysis Quality Initiative Definition of Cardiorenal Syndrome. ${ }^{47}$

\begin{tabular}{|c|l|l|}
\hline CRS Type & \multicolumn{1}{|c|}{ Inciting Event } & $\begin{array}{r}\text { Secondary } \\
\text { Disturbance }\end{array}$ \\
\hline $\mathbf{1}$ & Acute decompensated HF & Acute kidney injury \\
\hline $\mathbf{2}$ & Chronic HF & CKD \\
\hline $\mathbf{3}$ & Acute kidney injury & Acute HF \\
\hline $\mathbf{4}$ & CKD & Chronic HF \\
\hline $\mathbf{5}$ & $\begin{array}{l}\text { Co-development of HF and } \\
\text { CKD }\end{array}$ & \\
\hline
\end{tabular}

$\mathrm{CRS}=$ cardiorenal syndrome; $\mathrm{CKD}=$ chronic kidney disease; $\mathrm{HF}=$ heart failure.

women, anemia is frequently observed in patients with HF. Anemia in HFrEF is associated with more advanced disease, active ventricular remodeling processes, inflammation, renal dysfunction, and volume overload. ${ }^{13}$ The prevalence of anemia

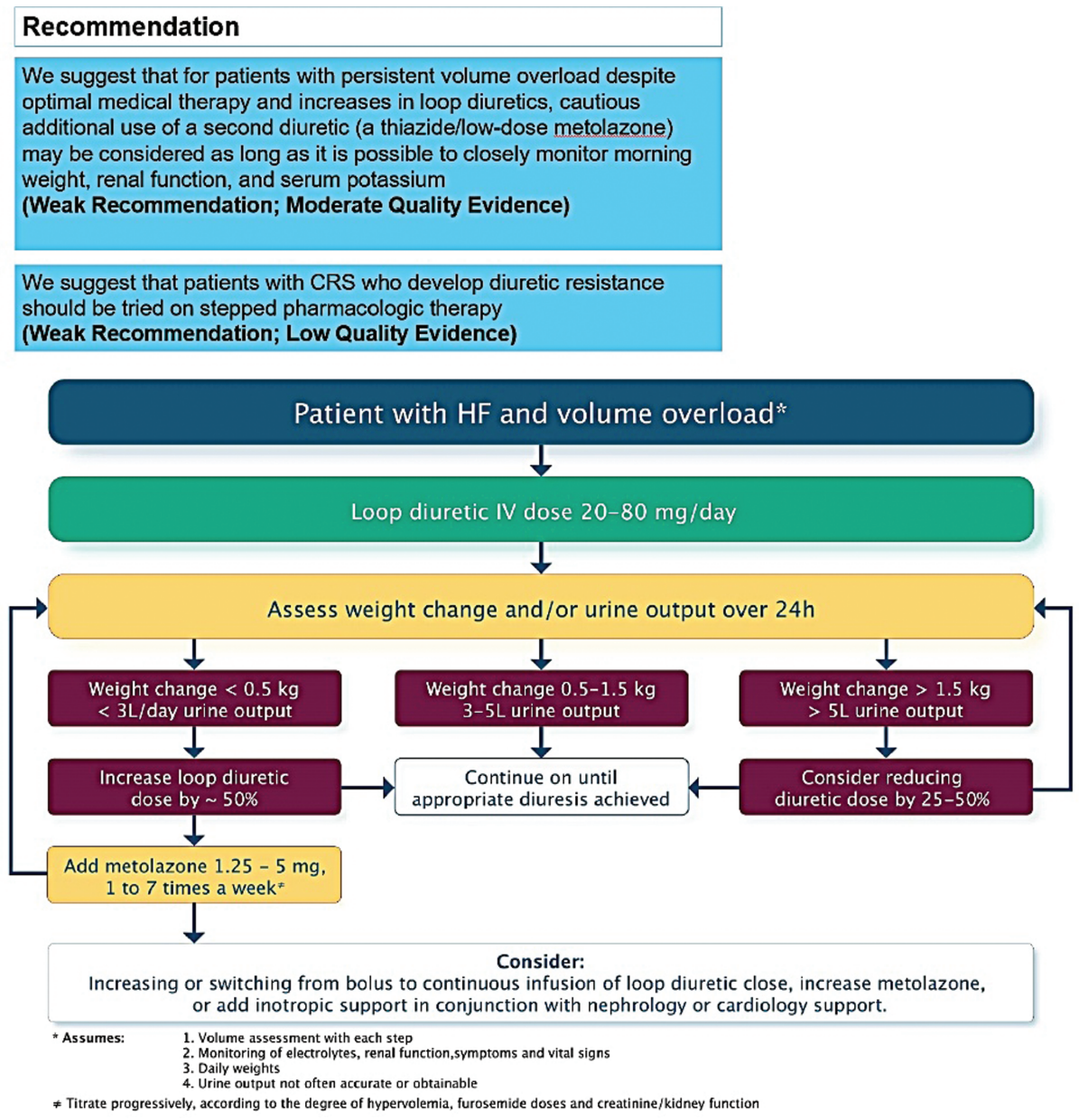

Figure 1. Canadian Cardiovascular Society Heart Failure 2017 Guideline Recommendations for the Management of Cardiorenal Syndrome. ${ }^{13}$ 
is similar irrespective of left ventricular ejection fraction ${ }^{20}$ and is estimated to be approximately $37 \%$ based on the findings from one meta-analysis. ${ }^{18}$ This meta-analysis also showed that after a minimum follow-up of 6 months, $46.8 \%$ of anemic patients died compared with $29.5 \%$ of non-anemic patients; (odds ratio [OR] = 1.96, 95\% CI: 1.74-2.21). ${ }^{21}$ Even small reductions in hemoglobin are associated with worse outcomes and symptom burden, including increased NYHA class and impairment in quality of life. ${ }^{19}$ Anemia is also associated with all-cause mortality ( $\mathrm{HR}=1.69,95 \% \mathrm{CI}$ : 1.22-2.35) and HF hospitalizations ( $\mathrm{HR}=1.44,95 \% \mathrm{CI}: 1.13-1.84$ ) in those living with $\mathrm{HF}^{2}$ Importantly, anemia may be reversible but the underlying pathophysiology of anemia in HF is complex and remains only partially understood.

The 2017 CCS HF Guidelines recommend against the routine use of erythropoietin stimulating agents to treat anemia in $\mathrm{HF}^{13}$ The two largest trials of erythropoietin stimulating agents in HF and a related meta-analysis failed to demonstrate benefits on mortality, cardiovascular events, and hospitalizations. ${ }^{22-24}$ In the Study of Anemia in HF Trial (STAMINA-HeFT), darbepoetin alfa treatment did not significantly improve exercise duration, NYHA class, or quality of life score compared with placebo.
Furthermore, in the Darbepoetin Alfa in HF (RED-HF) trial, a significant increase in thromboembolic events was reported in patients with a hemoglobin $>13 \mathrm{~g} / \mathrm{L} .^{23}$

While there has been continued interest in finding appropriate treatments for anemia in HF patients, more recent clinical trials have focused on iron deficiency as an appropriate therapeutic target (Figure 2). Iron deficiency in HF patients, with or without anemia also confers an increased risk of morbidity and mortality. ${ }^{22}$ The most widely accepted definition of iron deficiency is a serum ferritin $<100 \mathrm{mg} / \mathrm{L}$, or ferritin between 100 and $299 \mathrm{mg} / \mathrm{L}$ with transferrin saturation $<20 \%{ }^{13}$ Approximately one-half of patients with symptomatic $\mathrm{HF}$ are iron deficient. ${ }^{25}$ Based on contemporary clinical trials, intravenous but not oral iron therapy is recommended for the treatment of iron deficiency to improvement in clinical outcomes in patients with HFrEF. For example, in the Effect of Oral Iron Repletion on Exercise Capacity in Patients with HFrEF and Iron Deficiency (IRONOUT HF) trial, oral iron polysaccharide minimally repleted iron stores in patients with HFrEF and had no significant effect on exercise capacity when compared with placebo. ${ }^{25}$ In contrast, intravenous iron therapy improves exercise tolerance, quality of life, and reduces HF hospitalizations in

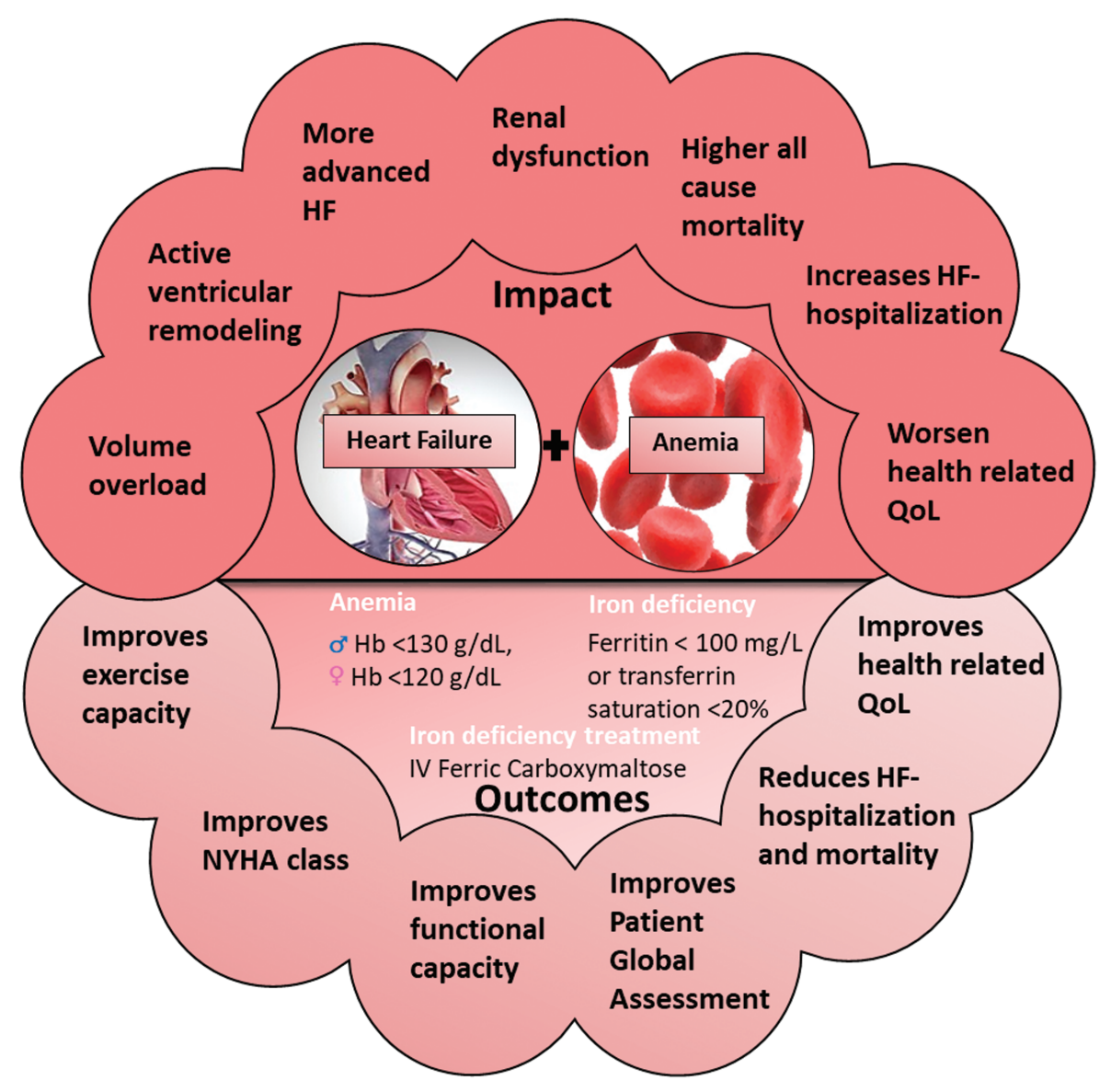

Figure 2. Iron deficiency and heart failure. 
patients with HFrEF and iron deficiency. ${ }^{13}$ This was demonstrated in two studies: The Ferric Carboxymaltose in Patients with HF and Iron Deficiency (FAIR HF) and Ferric Carboxymaltose Evaluation on Performance in Patients with Iron Deficiency in Combination with Chronic HF (CONFIRM HF) trials (Table 3). Specifically, FAIR HF and CONFIRM HF compared the use of intravenous ferric carboxymaltose versus placebo in HFrEF patients with iron deficiency (Table 3). Patients in the intravenous iron-supplementation arm experienced improved six-minute-walk test, NYHA class, patient global assessment, quality of life, and fatigue score when compared with placebo-treated patients. ${ }^{26,27}$ Further evidence is needed for iron supplementation for patients with HFpEF and established iron deficiency.

\section{Diabetes}

Diabetes is associated with an increased prevalence of both HFrEF and HFpEF. It is a risk factor for all-cause mortality $(\mathrm{HR}=1.74,95 \% \mathrm{CI}: 1.28-2.37$,$) and HF hospitalizations$
$(\mathrm{HR}=1.31,95 \% \mathrm{CI}: 1.04-1.65){ }^{2}$ The prevalence of diabetes in HF patients is estimated at $35 \% .{ }^{3}$ Epidemiological studies have shown that the incidence of HF is two to four times higher in patients with diabetes compared to those without diabetes. ${ }^{28}$ Also, increased glycated hemoglobin (HbAlc) and urinary albumin-to-creatinine ratio amongst patients with diabetes are associated with a two to four-fold increase in the risk of developing $\mathrm{HF}^{29}$

The Diabetes Canada 2018 Clinical Practice Guidelines outline therapeutic considerations for HF patients with diabetes. Overall, HF patients with diabetes should be treated similarly to those without diabetes with respect to renin angiotensin aldosterone system (RAAS) blockade and targeting a resting heart rate $<70$ beats per minute. ${ }^{30}$ Diabetes Canada also recommends carvedilol as the beta-blocker of choice in people with diabetes and $\mathrm{HF}$ as it has been shown to specifically improve glycemic control; however, the CCS HF Guidelines do not endorse a specific beta-blocker agent for this subgroup of patients. ${ }^{31}$

Table 3. Comparison of FAIR-HF and CONFIRM-HF Trials for IV Iron. ${ }^{26,27}$

\begin{tabular}{|c|c|c|}
\hline \multicolumn{2}{|r|}{ FAIR HF } & CONFIRM HF \\
\hline $\begin{array}{l}\text { Inclusion } \\
\text { criteria }\end{array}$ & $\begin{array}{l}\text { - } \text { LVEF } \leq 45 \% \text { with NYHA II-III symptoms } \\
\text { - } \text { LVEF } \leq 40 \% \text { with NYHA II symptoms } \\
\text { - Hemoglobin } 9.5 \text { - } 13.5 \mathrm{~g} / \mathrm{dL} \\
\text { - Iron deficiency: serum ferritin }<100 \mathrm{ug} / \mathrm{L} \text { or serum ferritin } 100 \\
-299 \mathrm{ug} / \mathrm{L} \text { and transferrin saturation }<20 \%\end{array}$ & $\begin{array}{l}\text { - } \mathrm{NYHA} \mathrm{II-III} \\
\text { - } \mathrm{LVEF} \leq 45 \% \\
\text { - } \mathrm{BNP}>100 \mathrm{pg} / \mathrm{mL} \text { or NT-pro BNP }>400 \mathrm{pg} / \mathrm{mL} \\
\text { - } \text { Iron deficiency: serum ferritin }<100 \mathrm{ng} / \mathrm{mL} \text { or } 100-300 \\
\mathrm{ng} / \mathrm{mL} \text { if transferrin saturation }<20 \%\end{array}$ \\
\hline Intervention & $\begin{array}{l}\text { - Randomized 2:1 ratio } \\
\text { IV iron (ferric carboxymaltose) } \\
\text { - Placebo } \\
\text { - } 24 \text { weeks }\end{array}$ & $\begin{array}{l}\text { - Randomized 1:1 } \\
\text { - IV iron (ferric carboxymaltose) } \\
\text { - Placebo } \\
\text { - } 52 \text { weeks }\end{array}$ \\
\hline $\begin{array}{l}\text { Primary } \\
\text { Outcomes }\end{array}$ & $\begin{array}{l}\text { - Improvement in Patient Global Assessment at week } 24 \text { (much or } \\
\text { moderately improved) } \\
\text { - } 50 \% \text { vs. } 28 \% \text { (OR for improvement } 2.51 ; 95 \% \mathrm{Cl} 1.75-3.61 \text {; } \\
\mathrm{p}<0.001 \text { ) } \\
\text { - Improvement in NYHA Class at week } 24 \text { (NYHA Class I or II) } \\
\text { - } 47 \% \text { vs. } 30 \% \text { (OR for improvement by one class } 2.40 ; 95 \% \mathrm{Cl} \\
1.55-3.71 ; p<0.001 \text { ) }\end{array}$ & $\begin{array}{l}\text { - Improved 6-minute walk distance at week } 24 \\
\text { - } 33 \pm 11 \text { meters, } p=0.002\end{array}$ \\
\hline $\begin{array}{l}\text { Secondary } \\
\text { Outcomes }\end{array}$ & $\begin{array}{l}\text { - 6-minute walk distance } \\
\text { - } 313 \text { meters vs. } 277 \text { meters }(p<0.001) \\
\text { - Kansas City Cardiomyopathy Questionnaire } \\
\text { - } 66 \text { vs. } 59(p<0.001) \\
\text { - EQ-5D Visual Assessment Scale } \\
\text { - } 63 \text { vs. } 57(p<0.001) \\
\text { - First hospitalization for cardiovascular reasons } \\
\text { - HR } 0.53 ; 95 \% \mathrm{Cl} 0.25-1.09 ; \mathrm{p}=0.08\end{array}$ & $\begin{array}{l}\text { - Changes in NYHA class } \\
\text { - Patient Global Assessment } \\
\text { - 6-minute walk distance } \\
\text { - Health-related quality of life } \\
\text { - Fatigue Score at Weeks } 6,12,24,36 \text {, and } 52 \\
\text { - Reduction in the risk of hospitalizations for worsening } \\
\text { HF } \\
\text { - HR } 0.39 ; 95 \% \mathrm{Cl} 0.19-0.82, \mathrm{p}=0.009\end{array}$ \\
\hline
\end{tabular}

BNP = B-type natriuretic peptide; EQ-5D = EuroQol-5D; HR = hazard ratio; IV = intravenous; LVEF = left ventricular ejection fraction; NYHA = New York Heart Association; NT-pro BNP = N-terminal pro b-type Natriuretic Peptide; $\mathrm{OR}=$ odds ratio. 
Regarding glycemic control, numerous studies evaluating different oral hypoglycemic agents and cardiovascular outcomes have been published (Table 4). Metformin is currently recommended as first-line anti-hyperglycemic therapy in HF patients with type 2 diabetes. ${ }^{30,32}$ In a more recent study looking at 12,156 patients with type 2 diabetes, metformin was associated with lower rates of all-cause mortality. ${ }^{33}$ In contrast, trials involving dipeptidyl peptidase-4 (DPP-4) inhibitors suggest a neutral impact on cardiovascular risk. The endpoint of noninferiority but not superiority was reached in the cardiovascular outcomes trials evaluating saxagliptin, sitagliptin and alogliptin. ${ }^{34-36}$ However, the Saxagliptin and Cardiovascular Outcomes in Patients with type 2 diabetes (SAVOR TIMI 53) trial demonstrated increased HF hospitalization. ${ }^{35}$ Thus, saxagliptin is not recommended for the treatment of diabetes in patients at risk for, or with, established HF.

Clinical trials investigating the glucagon-like peptide-1 (GLP-1) receptor agonists and cardiovascular outcomes included approximately $20 \%$ of patients with a history of HF. Overall, the data suggests no excess risk for HF hospitalization. ${ }^{37-39}$ In the Liraglutide and Cardiovascular Outcomes in type 2 diabetes (LEADER) trial, treatment with liraglutide was associated with a non-significant $13 \%$ reduction in HF hospitalization (HR = 0.87, 95\% CI: 0.73-1.05). ${ }^{39}$ Similarly, the Lixisenatide in Patients with T2DM and Acute Coronary Syndrome (ELIXA) and the Semaglutide and Cardiovascular Outcomes in Patients with type 2 diabetes (SUSTAIN-6) trials showed no significant association between treatment and rates of HF hospitalization. ${ }^{38}$

Historically classified as anti-hyperglycemic agents, sodiumglucose transport protein-2 (SGLT-2) inhibitors have emerged as important therapeutic agents given their favourable impact on cardiovascular outcomes, particularly related to consistently observed reductions in HF hospitalizations in a broad spectrum of patients with type 2 diabetes (Table 5). The first trial evaluating the SGLT-2 inhibitors was the Empagliflozin, Cardiovascular Outcomes, and Mortality trial (EMPA-REG OUTCOME). Empagliflozin reduced the rate of cardiovascular events and also conferred a $35 \%$ reduction in HF hospitalizations in patients with sub-optimally controlled diabetes and established cardiovascular disease when compared with placebo; $2.7 \%$ vs. $4.1 \%(\mathrm{HR}=0.65 ; 95 \% \mathrm{CI}: 0.50-0.85) .{ }^{40}$ A subsequent trial, the Canagliflozin and Cardiovascular and Renal Events in type 2 diabetes (CANVAS) trial, included a majority of patients with diabetes and cardiovascular disease; patients randomized to canagliflozin had a similar risk reduction in cardiovascular events and HF hospitalization compared to placebo. ${ }^{41}$ The clinical benefit of SGLT-2 inhibitors also translated to a lower risk profile population in the Dapagliflozin and Cardiovascular Outcomes in type 2 diabetes (DECLARE-TIMI 58) trial that included patients with multiple atherosclerotic risk factors. In this patient population, there was also a significant reduction in HF hospitalization for patients in the dapagliflozin group as compared with placebo ( $\mathrm{HR}=0.73$; 95\% CI: $0.61-0.88) .{ }^{42}$ Taken together, these landmark studies have formed the basis for the 2019 CCS HF Guideline recommendations for the use of SGLT-2 inhibitors to prevent HF hospitalization across a broad spectrum of risk in patients with type 2 diabetes. ${ }^{43}$

Lastly, thiazolidinediones are not recommended for patients with type 2 diabetes and HF due to an observed increase in fluid retention and HF events. In the Rosiglitazone Evaluated for

Table 4. Canadian Cardiovascular Society 2019 Recommendations for Anti-hyperglycemic Agents in Patients with Type 2 Diabetes ${ }^{43}$

\begin{tabular}{|c|c|c|c|}
\hline Class & Medication & Recommendation & Level of Evidence \\
\hline \multirow[b]{2}{*}{ SGLT-2 inhibitor } & $\begin{array}{l}\text { Empagliflozin } \\
\text { Canagliflozin } \\
\text { Dapagliflozin }\end{array}$ & $\begin{array}{l}\text { Used in patients with type } 2 \text { diabetes and } \\
\text { established atherosclerotic cardiovascular disease } \\
\text { to reduce the risk for HF hospitalization and death }\end{array}$ & Strong Recommendation; High-Quality Evidence \\
\hline & Dapagliflozin & $\begin{array}{l}\text { Used in patients with type } 2 \text { diabetes aged }>50 \\
\text { years with additional risk factors for atherosclerotic } \\
\text { cardiovascular disease to reduce the risk of HF } \\
\text { hospitalization }\end{array}$ & Strong Recommendation; High-Quality Evidence \\
\hline Biguanide & Metformin & $\begin{array}{l}\text { May be considered a first-line agent for type } 2 \\
\text { diabetes treatment }\end{array}$ & Weak Recommendation; Moderate-Quality Evidence \\
\hline Thiazolidinedione & $\begin{array}{l}\text { Pioglitazone } \\
\text { Rosiglitazone }\end{array}$ & $\begin{array}{l}\text { Should NOT be used in patients with HF as they } \\
\text { have been shown in studies to increase the risk for } \\
\text { HF }\end{array}$ & Strong Recommendation; High-Quality Evidence \\
\hline
\end{tabular}

$\mathrm{HF}=$ heart failure; SGLT-2 = sodium-glucose transport protein 2. 
Table 5. Summary of Sodium-Glucose Transport Protein 2 Inhibitor Trials and Cardiovascular Outcomes

\begin{tabular}{|c|c|c|c|c|c|c|}
\hline & & & \multicolumn{4}{|c|}{ Secondary Outcomes } \\
\hline Trial & Medication & Primary Outcome & CV Death & $\begin{array}{c}\text { Nonfatal } \\
\text { MI }\end{array}$ & $\begin{array}{l}\text { Nonfatal } \\
\text { Stroke }\end{array}$ & HFH \\
\hline $\begin{array}{l}\text { EMPA-REG } \\
\text { OUTCOME (40) }\end{array}$ & Empagliflozin & $\begin{array}{l}\text { CV death/MI/Stroke } \\
\text { HR } 0.86 \\
(95 \% \mathrm{Cl} 0.74-0.99)\end{array}$ & $\begin{array}{c}\text { HR } 0.62 \\
(95 \% \mathrm{Cl} 0.49-0.77)\end{array}$ & NS & NS & $\begin{array}{l}\text { HR } 0.65 \\
(95 \% \mathrm{Cl} 0.50-0.85)\end{array}$ \\
\hline $\begin{array}{l}\text { CANVAS } \\
(41)\end{array}$ & Canagliflozin & $\begin{array}{l}\text { CV death/MI/Stroke } \\
\text { HR } 0.86 \\
(95 \% \mathrm{Cl} 0.75-0.97)\end{array}$ & NS & NS & NS & $\begin{array}{l}\text { HR } 0.67 \\
(95 \% \mathrm{Cl} 0.52-0.87)\end{array}$ \\
\hline $\begin{array}{l}\text { DECLARE-TIMI } 58 \\
\text { (42) }\end{array}$ & Dapagliflozin & $\begin{array}{l}\text { CV death/HFH } \\
\text { HR } 0.83 \\
\text { ( } 95 \% \mathrm{CI} 0.73-0.95) \\
\text { CV death/MI/Stroke } \\
\text { NS }\end{array}$ & NS & NS & NS & $\begin{array}{l}\text { HR } 0.73 \\
(95 \% \mathrm{Cl} 0.61-0.88)\end{array}$ \\
\hline
\end{tabular}

$\mathrm{CV}$ = cardiovascular; $\mathrm{Cl}=$ confidence interval; $\mathrm{HFH}=$ heart failure hospitalization; $\mathrm{HR}=$ hazard ratio; $\mathrm{MI}=$ myocardial infarction; $\mathrm{NS}=$ not significant.

Cardiovascular Outcomes in Oral Agent Combination Therapy for T2DM (RECORD) study, 4,447 patients with type 2 diabetes on metformin or sulfonylurea monotherapy who received add-on rosiglitazone experienced a 2-fold risk of HF death or hospitalization $(\mathrm{HR}=2.10,95 \% \mathrm{CI}: 1.35-3.27){ }^{44}$

In conclusion, non-cardiac comorbidities significantly impact patients with HF. Comorbid CKD, anemia, and diabetes are independently associated with both mortality and HF hospitalization. The prevalence of these conditions in the setting of HF, their impact on clinical outcomes, and the recommended management have been reviewed here, taking into account recent trials with an evidence-based update. Ultimately, a multidisciplinary approach that considers individual patients in the context of competing risks and comorbidities is vital for optimal care in HF.

\section{References}

1. The Burden of Heart Failure: The Heart and Stroke Foundation; 2016. Available from: https://www.heartandstroke.ca/-/media/pdf-files/ canada/2017-heart-month/heartandstroke-reportonhealth-2016.ashx?la=en.

2. van Deursen VM, Urso R, et al. Co-morbidities in patients with heart failure: an analysis of the European Heart Failure Pilot Survey. Eur J Heart Fail 2014;16(1):103-11.

3. Rashid M, Kwok CS, Gale CP, et al. Impact of co-morbid burden on mortality in patients with coronary heart disease, heart failure, and cerebrovascular accident: a systematic review and meta-analysis. Eur Heart J Qual Care Clin Outcomes 2017;3(1):20-36.

4. Mamas MA, Sperrin M, Watson MC, et al. Do patients have worse outcomes in heart failure than in cancer? A primary care-based cohort study with 10year follow-up in Scotland. Eur J Heart Fail 2017;19(9):1095-104.

5. Ponikowski P, Voors AA, Anker SD, et al. 2016 ESC Guidelines for the diagnosis and treatment of acute and chronic heart failure: The Task Force for the diagnosis and treatment of acute and chronic heart failure of the European Society of Cardiology (ESC). Developed with the special contribution of the Heart Failure Association (HFA) of the ESC. Eur J Heart Fail 2016;18(8):891-75.

6. Group CTS. Effects of enalapril on mortality in severe congestive heart failure. Results of the Cooperative North Scandinavian Enalapril Survival Study (CONSENSUS). N Engl J Med 1987;316(23):1429-35.

7. McMurray JJ, Packer M, Desai AS, et al. Angiotensin-neprilysin inhibition versus enalapril in heart failure. N Engl J Med 2014;371(11):993-1004.

8. McMurray JJV, Solomon SD, Inzucchi SE, et al. Dapagliflozin in patients with heart failure and reduced ejection fraction. $\mathrm{N}$ Engl J Med 2019;381(21):1995-2008.

9. Solomon SD, McMurray JJV, Anand IS, et al. Angiotensin-neprilysin inhibition in heart failure with preserved ejection fraction. N Engl J Med 2019;381(17):1609-20.

10. Ahmed A, Campbell RC. Epidemiology of chronic kidney disease in heart failure. Heart Fail Clin 2008;4(4):387-99.

11. Heywood JT, Fonarow GC, Costanzo MR, et al. High prevalence of renal dysfunction and its impact on outcome in 118,465 patients hospitalized with acute decompensated heart failure: a report from the ADHERE database. J Card Fail 2007;13(6):422-30.

12. Smith GL, Lichtman JH, Bracken MB, et al. Renal impairment and outcomes in heart failure: systematic review and meta-analysis. J Am Coll Cardiol 2006;47(10):1987-96.

13. Ezekowitz JA, O'Meara E, McDonald MA, et al. 2017 Comprehensive Update of the Canadian Cardiovascular Society Guidelines for the Management of Heart Failure. Can J Cardiol 2017;33(11):1342-33.

14. Felker GM, Lee KL, Bull DA, et al. Diuretic strategies in patients with acute decompensated heart failure. N Engl J Med 2011;364(9):797-805.

15. Costanzo MR, Guglin ME, Saltzberg MT, et al. Ultrafiltration versus intravenous diuretics for patients hospitalized for acute decompensated heart failure. J Am Coll Cardiol 2007;49(6):675-83.

16. Bart BA, Goldsmith SR, Lee KL, et al. Ultrafiltration in decompensated heart failure with cardiorenal syndrome. N Engl J Med 2012;367(24):2296-304.

17. Liu PP. Cardiorenal syndrome in heart failure: a cardiologist's perspective. Can J Cardiol 2008;24 Suppl B:25B-9B.

18. Rangaswami J, Bhalla V, Blair JEA, et al. Cardiorenal syndrome: Classification, pathophysiology, diagnosis, and treatment strategies: a scientific statement from the American Heart Association. Circulation 2019;139(16):e840-e78. 
19. Anand IS, Kuskowski MA, Rector TS, et al. Anemia and change in hemoglobin over time related to mortality and morbidity in patients with chronic heart failure: results from Val-HeFT. Circulation 2005;112(8):1121-7.

20. O'Meara E, Clayton T, McEntegart MB, et al. Clinical correlates and consequences of anemia in a broad spectrum of patients with heart failure: results of the Candesartan in Heart Failure: Assessment of Reduction in Mortality and Morbidity (CHARM) Program. Circulation. 2006;113(7):986-94.

21. Groenveld HF, Januzzi JL, Damman K, et al. Anemia and mortality in heart failure patients a systematic review and meta-analysis. J Am Coll Cardiol 2008;52(10):818-27.

22. Arora NP, Ghali JK. Anemia and iron deficiency in heart failure. Heart Fail Clin 2014;10(2):281-94.

23. Swedberg K, McMurray JJ, Young JB. Darbepoetin alfa in systolic heart failure. N Engl J Med 2013;369(5):488-9.

24. Ghali JK, Anand IS, Abraham WT, et al. Randomized double-blind trial of darbepoetin alfa in patients with symptomatic heart failure and anemia. Circulation 2008;117(4):526-35.

25. Lewis GD, Malhotra R, Hernandez AF, et al. Effect of oral iron repletion on exercise capacity in patients with heart failure with reduced ejection fraction and iron deficiency: The IRONOUT HF Randomized Clinical Trial. JAMA 2017;317(19):1958-66.

26. Anker SD, Comin Colet J, et al. Ferric carboxymaltose in patients with heart failure and iron deficiency. N Engl J Med 2009;361(25):2436-48.

27. Ponikowski P, van Veldhuisen DJ, Comin-Colet J, et al. Beneficial effects of long-term intravenous iron therapy with ferric carboxymaltose in patients with symptomatic heart failure and iron deficiency. Eur Heart J 2015;36(11):657-68.

28. Shimabukuro M, Higa N, Oshiro Y, Asahi T, Takasu N. Diagnostic utility of brain-natriuretic peptide for left ventricular diastolic dysfunction in asymptomatic type 2 diabetic patients. Diabetes Obes Metab 2007;9(3):323-9.

29. Didangelos TP, Arsos GA, Karamitsos DT, Athyros VG, Karatzas ND. Left ventricular systolic and diastolic function in normotensive type 1 diabetic patients with or without autonomic neuropathy: a radionuclide ventriculography study. Diabetes Care 2003;26(7):1955-60.

30. Lipscombe L, Booth G, Butalia S, et al. Pharmacologic glycemic management of type 2 diabetes in adults. Can J Diabetes 2018;42 Suppl 1:S88-S103.

31. Haas SJ, Vos T, Gilbert RE, Krum H. Are beta-blockers as efficacious in patients with diabetes mellitus as in patients without diabetes mellitus who have chronic heart failure? A meta-analysis of large-scale clinical trials. Am Heart J 2003;146(5):848-53.

32. Andersson C, Olesen JB, Hansen PR, et al. Metformin treatment is associated with a low risk of mortality in diabetic patients with heart failure: a retrospective nationwide cohort study. Diabetologia 2010;53(12):2546-53.

33. Bergmark BA, Bhatt DL, McGuire DK, et al. Metformin use and clinical outcomes among patients with diabetes mellitus with or without heart failure or kidney dysfunction: observations from the SAVOR-TIMI 53 Trial. Circulation 2019;140(12):1004-14.

34. White WB, Cannon CP, Heller SR, et al. Alogliptin after acute coronary syndrome in patients with type 2 diabetes. $\mathrm{N}$ Engl J Med 2013;369(14):1327-35.

35. Scirica BM, Bhatt DL, Braunwald E, et al. Saxagliptin and cardiovascular outcomes in patients with type 2 diabetes mellitus. N Engl J Med 2013;369(14):1317-26.

36. Green JB, Bethel MA, Armstrong PW, et al. Effect of sitagliptin on cardiovascular outcomes in type 2 diabetes. N Engl J Med 2015;373(3):232-42.

37. Marso SP, Bain SC, Consoli A, et al. Semaglutide and cardiovascular outcomes in patients with type 2 diabetes. $\mathrm{N}$ Engl J Med 2016;375(19):1834-44.

38. Pfeffer MA, Claggett B, Diaz R, et al. Lixisenatide in Patients with Type 2 Diabetes and Acute Coronary Syndrome. N Engl J Med. 2015;373(23):2247-57.

39. Marso SP, Daniels GH, Brown-Frandsen K, et al. Liraglutide and cardiovascular outcomes in type 2 diabetes. $\mathrm{N}$ Engl J Med 2016;375(4):311-22.

40. Zinman B, Wanner C, Lachin JM, et al. Empagliflozin, cardiovascular outcomes, and mortality in type 2 diabetes. $\mathrm{N}$ Engl J Med 2015;373(22):2117-28.

41. Neal B, Perkovic V, Matthews DR. Canagliflozin and cardiovascular and renal events in type 2 diabetes. N Engl J Med 2017;377(21):2099.

42. Wiviott SD, Raz I, Bonaca MP, et al. Dapagliflozin and cardiovascular outcomes in type 2 diabetes. N Engl J Med 2019;380(4):347-57.

43. O’Meara E, McDonald M, Ducharme A, Toma M, Howlett J, Virani S. Canadian Cardiovascular Society Heart Failure Guidelines: Clinical Trials Update Montreal, Quebec, Canada: Canadian Cardiovascular Congress 2019; 2019 [Available from: https://www.eventscribe.com/2019/CCS/fsPopup. asp?efp=R0lWUlhRSUY0MzIx\&PresentationID=579526\&rnd=0.3740588\&mode=presinfo.

44. Home PD, Pocock SJ, Beck-Nielsen H, et al. Rosiglitazone evaluated for cardiovascular outcomes in oral agent combination therapy for type 2 diabetes (RECORD): a multicentre, randomised, open-label trial. Lancet 2009;373(9681):2125-35.

45. Rocha BML, Cunha GJL, Menezes Falcão LF. The burden of iron deficiency in heart failure: therapeutic approach. J Am Coll Cardiol 2018;71(7):782-93.

46. New York: National Kidney Foundation; 2019 [Available from: https://www. kidney.org/atoz/content/gfr.

47. Ronco C, McCullough P, Anker SD, et al. Cardio-renal syndromes: report from the consensus conference of the acute dialysis quality initiative. Eur Heart J 2010;31(6):703-11. 